\title{
Características Morfogênicas e Acúmulo de Forragem do Capim-Tanzânia (Panicum maximum Jacq. cv. Tanzânia) em Dois Resíduos Forrageiros Pós-Pastejo ${ }^{1}$
Rodrigo Amorim Barbosa², Domicio do Nascimento Júnior ${ }^{3}$, Valéria Pacheco Batista Euclides ${ }^{4}$, Adair José Regazzi ${ }^{5}$, Dilermando Miranda da Fonseca ${ }^{3}$

RESUMO - O experimento foi conduzido no Centro Nacional de Gado de Corte da Empresa Brasileira de Pesquisa Agropecuária (Embrapa Gado de Corte). Foram avaliadas as características morfogênicas de folhas e perfilhos, acúmulo de matéria seca verde e índices de crescimento do capim-tanzânia em dois resíduos forrageiros pós-pastejo (Resíduo alto - RA 3,6 t de MS/ha e Resíduo baixo - RB $2,3 \mathrm{t}$ de $\mathrm{MS} / \mathrm{ha}$ ), até os 35 dias após o pastejo. O delineamento experimental foi em blocos casualizados completos com os tratamentos no esquema de parcelas subdivididas com três repetições. Para a dinâmica de perfilhamento houve diferença entre resíduos somente no aparecimento de novos perfilhos basilares. A taxa de aparecimento de novos perfilhos, tanto basilares quanto aéreos, decresceu linearmente com os dias de rebrotação após o pastejo. As taxas de alongamento e senescência de folhas não diferiram entre resíduos e tipos de perfilho. Em contrapartida, a duração de alongamento foliar foi menor no resíduo baixo e no perfilho novo, porém produzindo folhas com menor comprimento final. Houve interação entre resíduo e tipo de perfilho para a taxa de aparecimento de folhas, com maiores valores para o resíduo baixo no perfilho novo e remanescente. O acúmulo de matéria seca verde não diferiu entre resíduos, sendo, em média, 61,4 e 47,9 kg/ha.dia, nos resíduos baixo e alto, respectivamente. A taxa de crescimento relativo e o índice de área foliar não apresentaram diferenças entre resíduos forrageiros, porém apresentaram comportamento inverso em função dos dias após o pastejo.

Palavras-chave: manejo, morfogênese, perfilhamento, rebrotação

\section{Morphogenetic Characteristics and Forage Accumulation of Tanzania Grass (Panicum Maximum Jacq.) in Two Post-Graze Stubbles}

\begin{abstract}
This trial was conducted at National Beef Cattle Research Center of Brazilian Agricultural Research Corporation (Embrapa Beef Cattle), to evaluate the morphogenetic characteristics of leaves and tiller, green dry matter yield and growth index of Tanzaniagrass in two post-graze stubbles (high post-graze stubble (HPS) - $3.6 \mathrm{t}$ of DM/ha and low post-graze stubble (LPS) - $2.3 \mathrm{t}$ of DM/ha) until 35 days after grazing. The experimental design was a complete randomized block, with treatments assigned to a split plot design, with three replicates. Differences between post-graze stubble (PS) in the tiller dynamics only occurred to new basal tiller. The appearance of new basal tillers and new aerial tillers linearly decreased during the days after grazing. There was no difference between the post-graze stubble and the new and remaining tillers for the leaf elongation rate and leaf senescence. On the other hand, the leaf duration of elongation was lower in the low PS and the new tillers, producing leaves with lower fully length. There was interaction in the leaf appearance rate between PS and kind of tillers, with a higher one for low PS in the remaining and new tiller. There was no difference among the post-graze stubbles for green dry matter yield, with mean values of 61.4 and $47.9 \mathrm{~kg} / \mathrm{ha}$.day, for low and high PS, respectively. There was also no difference between high and low PS for the relative growth rate and leaf area index (LAI). However, the LAI increased, as a function of to the days after grazing.
\end{abstract}

Key Words: management, morphogenesis, regrowth, tillering

\section{Introdução}

Gramíneas forrageiras são plantas extremamente adaptadas ao pastejo pois, antes do início do estádio de florescimento, ocorre a contínua emissão de folhas logo após a desfolhação. Isto se deve ao fato de que, durante a fase vegetativa, a zona meristemática se encontra próxima ao nível do solo e, portanto, longe do alcance dos animais. Ainda, se alguns meristemas forem removidos, estes rapidamente serão repostos pelo aparecimento de novos perfilhos (Langer, 1972).

O entendimento da capacidade da planta em rebrotar após desfolhação vem sendo foco de pesquisas na últimas décadas. Segundo Grant \& Marriot (1994),

\footnotetext{
${ }_{1}^{1}$ Parte da tese de Mestrado apresentada à UFV.

2 Estudante de Doutorado/UFV. E.mail: rodrigo@correio.ufv.br

3 Professor do DZO/UFV. E.mail: domicion@ufv.br

${ }^{4}$ Pesquisador da EMBRAPA/Gado de Corte. E.mail: val@cnpgc.embrapa.br

${ }^{5}$ Professor do DPI.
} 
a busca de informações mais detalhadas sobre as medidas dos componentes de crescimento do pasto, aliados com os efeitos do ambiente e manejo, data da década de 60 , em que o principal objetivo era o incremento da produtividade.

Dessa forma, tornaram-se relevantes estudos na dinâmica de produção primária das gramíneas forrageiras, por meio de avaliações de características morfogênicas, uma vez que estes permitem uma análise do crescimento vegetal. Com isso, pode-se ter uma estimativa da produção forrageira, bem como de sua taxa de acúmulo de matéria seca. Estes estudos podem gerar conhecimentos básicos necessários para definições de estratégias de manejo para plantas forrageiras nas mais variadas condições.

Objetivou-se com este trabalho determinar as características morfogênicas de folhas e perfilhos e o acúmulo de forragem do capim-tanzânia (Panicum maximum Jacq. cv. Tanzânia), em dois resíduos forrageiros pós-pastejo, até os 35 dias após o início da rebrotação.

\section{Material e Métodos}

O experimento foi conduzido na EMBRAPA Gado de Corte (CNPGC), em Campo Grande, MS (Lat. 20² $27^{\prime}$ Sul, Long. $54^{\circ} 37^{\prime}$ Oeste e Alt. 530m). A área experimental está localizada em um solo da classe Latossolo Vermelho Escuro, álico - fase cerradão, caracterizado por textura argilosa, $\mathrm{pH}$ ácido, baixa saturação por bases e alta concentração de alumínio. O clima, segundo a classificação de Köppen, é do tipo tropical chuvoso de savana, subtipo Aw, com ocorrência bem definida do período seco nos meses de maio a setembro e do período chuvoso nos meses de outubro a abril.

Dados referentes ao clima, como precipitação pluvial, umidade média relativa do ar e temperaturas máximas, médias e mínimas diárias obtidas pela estação meteorológica da EMBRAPA - Gado de Corte, estão apresentados na Figura 1. Durante o período experimental, a precipitação pluvial total foi de 216,6 mm, valores extremamente baixos para esta época do ano. O ano de 1999 foi altamente atípico na quantidade de chuva, onde o balanço hídrico apresentou um déficit de $252 \mathrm{~mm}$ no ano, quando comparado à média dos 26 anos anteriores.

Na segunda quinzena de setembro de 1999 , foram aplicados $2 \mathrm{t} /$ ha de calcário dolomítico (PRNT 90\%), $444 \mathrm{~kg} /$ ha da fórmula 0-20-20 e 27,3 kg/ha de BR 12 ,

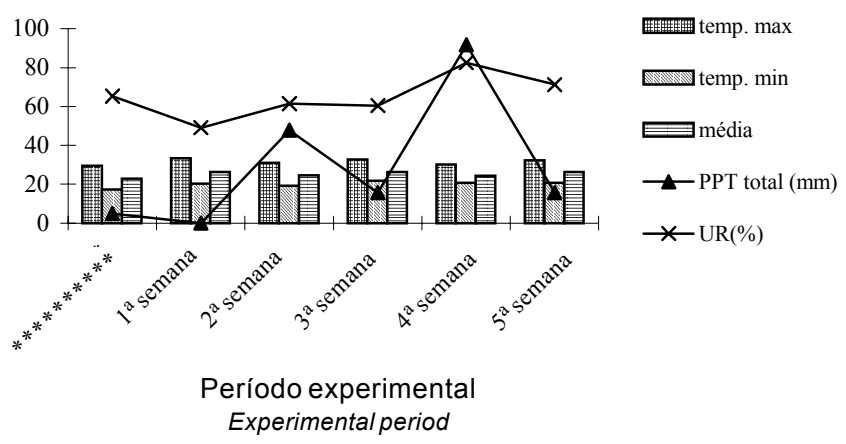

**** Entrada dos animais nos piquetes (Beginning of the grazing cycle).

Figura 1 - Temperaturas máximas, médias e mínimas (média semanal), precipitação total e umidade média relativa registrada de 04/11/1999 a 16/12/1999, em Campo Grande, MS.

Figure 1 - Maximum, medium and minimum temperatures (weekly mean), rainfall and average relative humidity recorded from 11/04/1999 to 12/16/1999, at Campo Grande - MS

para elevar a saturação por bases a $50-70 \%$, o teor de fósforo para $8-12 \mathrm{mg} / \mathrm{dm}^{3}(\mathrm{P}-$ Mehlich1) e o de potássio para $80-100 \mathrm{mg} / \mathrm{dm}^{3}$.

A área utilizada no experimento foi de 1,14 ha, subdividida em seis piquetes de 0,19 ha cada. Para obtenção dos resíduos de forragem, primeiramente foi estimada a disponibilidade de forragem antes do pastejo, no dia 04/11/1999, que foi feita com a coleta de 15 amostras/piquete, cortadas ao nível do solo, em $1 \mathrm{~m}^{2}$ de área, sendo posteriormente levadas ao laboratório para determinação do peso seco. De posse desta informação, estimou-se a disponibilidade de forragem, que foi de 4,1 t de MS/ha. No dia 11/11/1999, para obtenção dos resíduos forrageiros pós-pastejo, foram utilizados animais mestiços $\left(\mathrm{F}_{1}\right.$ Nelore $\mathrm{x}$ Limousin) com peso vivo médio de $302 \mathrm{~kg}$ durante sete dias, sendo o número de animais de três e seis para os resíduos alto e baixo, respectivamente. Após a retirada dos animais dos piquetes, foram tomadas, ao acaso, 15 amostras de $1 \mathrm{~m}^{2}$ por piquete, sendo executadas as mesmas atividades para estimativa da disponibilidade. Dessa forma, os resíduos forrageiros pós-pastejo foram de 2,3 e 3,6 t de MS/ha para os resíduos baixo e alto, respectivamente. De forma prática, a altura média das plantas após o pastejo no resíduo baixo estava em torno de $25 \mathrm{~cm}$, enquanto, no resíduo alto, as plantas se aproximavam de $40 \mathrm{~cm}$. Também, após a saída dos animais dos piquetes, no 
dia 11 de novembro, foram aplicados, em cobertura, $220 \mathrm{~kg} /$ ha de uréia. No dia 24/11, foi feita aplicação, com pulverizador costal, do inseticida "Karate 50CE" na quantidade de $40 \mathrm{~mL} /$ piquete para o controle de lagarta-do-cartucho (Spodoptera frugiperda).

$\mathrm{O}$ delineamento experimental foi em blocos casualizados completos, com os tratamentos no esquema de parcelas subdivididas com três repetições. Para as variáveis peso seco de perfilhos, índice de área foliar, relação folha:colmo e taxa de crescimento relativo, os resíduos de forragem pós-pastejo (resíduo alto - RA 3,6 t de MS/ha e resíduo baixo - RB 2,3 t de MS/ha) constituíram as parcelas e os dias de avaliação após o pastejo (7, 14, 21, 28 e 35 dias), as subparcelas. Para determinação da dinâmica de perfilhamento, as avaliações foram feitas aos 8, 16, 24 e 32 dias (subparcelas) após o pastejo. Já para as variáveis morfogênicas, as subparcelas foram constituídas pelo tipo de perfilho (perfilho novo e perfilho remanescente).

Ao final do período de pastejo, para determinação do aparecimento, alongamento, duração de alongamento e senescência de folhas de perfilhos basilares, foram tomados, ao acaso, 30 perfilhos por piquete, sendo 15 perfilhos novos e 15 remanescentes póspastejo. Os perfilhos foram identificados com anéis plásticos e, para melhor visualização no campo, ao lado de cada perfilho, foi fixado arame com fita numerada. Duas vezes por semana, foi medido o comprimento de lâminas foliares. A partir deste valor, calcularam-se o aparecimento de folhas (folhas/ dia.perfilho), alongamento (cm de folha/dia.perfilho), duração de alongamento (dias), comprimento final de lâmina foliar $(\mathrm{cm})$ e senescência de folhas (cm/dia.perfilho).

Para estimar a contribuição dos diferentes tipos de perfilho para a rebrotação das plantas, após o ciclo de pastejo, foram sorteadas 10 touceiras por repetição, entre pequenas (até 40 perfilhos remanescentes), médias (entre 41 e 70 perfilhos remanescentes) e grandes (acima de 70 perfilhos remanescentes). Foram contados os seguintes tipos de perfilhos: basilar remanescente, aéreo remanescente, basilar novo, aéreo novo e decapitado (meristema apical eliminado) (Figuras 2, 3 e 4). A contagem dos perfilhos novos foi realizada a cada oito dias. Para identificação das touceiras sorteadas, utilizou-se o mesmo método do arame com fita numerada e em volta de cada touceira foi colocado barbante para melhor identificação.

A determinação do acúmulo de matéria seca verde (AMSV) e da relação lâmina foliar verde:colmo

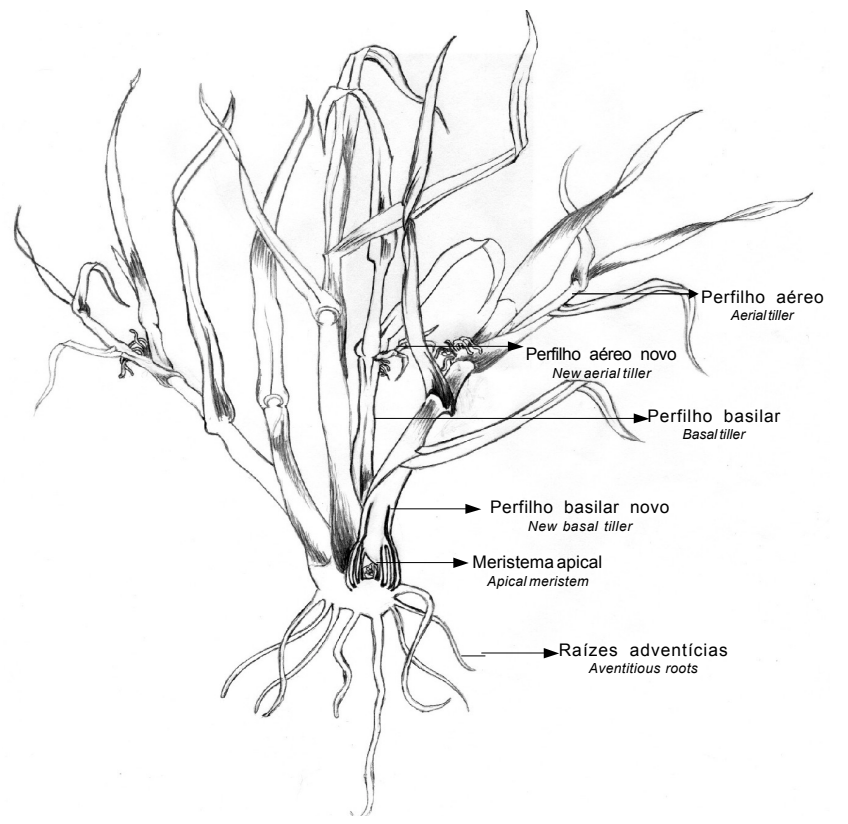

Figura 2 - Esquema de uma gramínea caracterizando os perfilhos basilares e aéreos. Adaptado de Langer (1972) e Jewiss (1972).

Figure 2 - Diagram of grass plant characterizing the aerial and basal tillers. Adapted from Langer (1972) and Jewiss (1972).

+ bainha foi feita por meio da coleta, ao acaso, de 12 amostras por piquete, cortadas ao nível do solo, em área de $1 \mathrm{~m}^{2}$. Após o corte, as amostras foram acondicionadas em sacos plásticos, sendo posteriormente levadas ao laboratório, onde foram pesadas, ainda verdes, e subdivididas em duas subamostras. A primeira fração da amostra foi pesada, e logo após, colocada em saco de papel, sendo levada à estufa para secagem a $60^{\circ} \mathrm{C}$, até peso constante, para estimativa da matéria seca (MS). De posse do peso total da amostra e da MS, determinou-se o acúmulo de matéria seca verde (AMSV). A segunda fração de cada amostra foi utilizada para separação em lâmina foliar verde, colmo + bainha e material morto.

Após a separação botânica, $15 \%$ da subamostra de lâmina foliar foi pesada ainda verde e passada no medidor de área foliar tipo LICOR LI 3000. As demais frações (restante das folhas, colmo + bainha e material morto) foram levadas à estufa para determinação do peso seco. Após a determinação da área foliar, estas folhas também foram secas até peso constante e, posteriormente, somadas com o restante das folhas para determinação do peso seco total de folhas. 
(a)

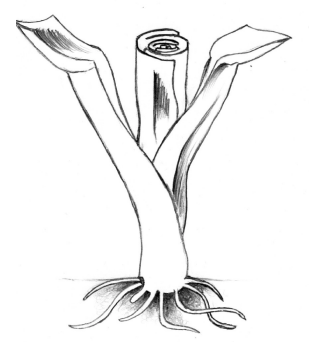

(b)

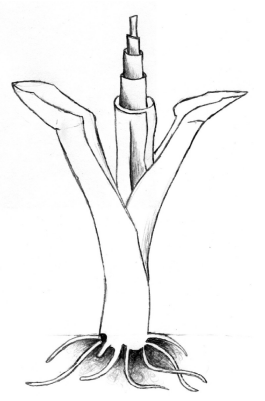

(c)

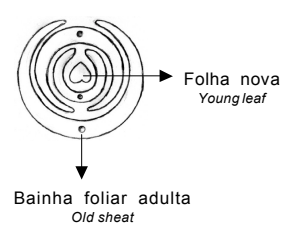

Old sheat
Figura 3 - Perfilho basilar logo após a desfolhação (a) e poucos dias depois (b). Note que neste caso, não houve remoção do meristema apical e a emissão de folhas é contínua. A figura (c) refere-se à figura (b) vista de cima. Adaptado de Langer (1972).

Figure 3 - Basal tiller immediately after defoliation (a) and few days later (b). Note that the shoot apex has not been removed and the emission of leaves is continuous. Diagram (c) refers to diagram (b) seen from the top. Adapted from Langer (1972).

De posse dos valores de matéria seca total, peso seco de folhas e área foliar, foram determinados os índices fisiológicos: taxa de crescimento relativo (TCR) e índice de área foliar (IAF), de acordo com o proposto por Beadle (1993).

Para os cálculos de TCR e IAF, foram utilizadas as seguintes equações:

$$
\begin{gathered}
\mathrm{TCR}=\left(\ln \mathrm{W}_{2}-\ln \mathrm{W}_{1}\right) /\left(\mathrm{T}_{2}-\mathrm{T}_{1}\right) \\
\mathrm{IAF}=\mathrm{AF} / \mathrm{AT}
\end{gathered}
$$

em que: $\mathrm{W}_{2}-\mathrm{W}_{1}=$ diferença de peso seco entre duas amostragens semanais consecutivas em $1 \mathrm{~m}^{2}$ de área;

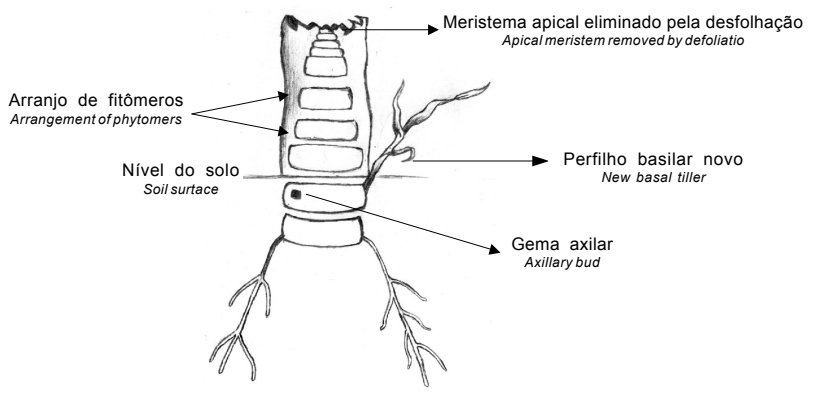

Figura 4 - Perfilho remanescente decapitado após a desfolhação e aparecimento de um novo perfilho basilar a partir de uma gema axilar. Adaptado de Valentine \& Matthew (1999).

Figura 4 - Remaining tiller decapitated after defoliation and appearance of new basal tiller from the axillary bud. Adapted from Valentine \& Matthew (1999).
$\mathrm{AF}=$ área foliar da amostra; AT = área do terreno; $\mathrm{T}=$ tempo em dias; $\mathrm{ln}=$ logaritmo neperiano.

As análises estatísticas foram feitas utilizando-se o sistema para análise estatística - SAS (1993), mediante análise de variância e análise de regressão.

\section{Resultados e Discussão}

\section{Dinâmica de perfilhamento e peso seco de perfilhos remanescentes}

O número de perfilhos decapitados por touceira (Tabela 1) não apresentou diferença $(\mathrm{P}>0,05)$ entre os resíduos utilizados. Observou-se reduzido número de perfilhos decapitados, nos dois resíduos forrageiros pós-pastejo, que pode ser atribuído à localização do meristema apical, que, no estado vegetativo da planta, se encontra perto do nível do solo e envolto por bainhas de folhas adultas formando o pseudocolmo. Esta característica oferece proteção ao meristema apical contra danos ou remoção pela desfolhação (Valentine \& Matthew, 1999). Provavelmente, o baixo número de perfilhos decapitados foi devido à taxa de lotação implantada, para obtenção dos resíduos, que proporcionou seletividade por parte dos animais que preferem folhas a colmos, com conseqüente redução na chance de remoção de meristema apical. Entretanto, Coelho et al. (1999), trabalhando com quatro cultivares de Panicum maximum, no período de janeiro a março, encontraram maior número de perfilhos decapitados, por touceira, em cortes a $20 \mathrm{~cm}(15,3 \%)$, quando comparados com cortes a $40 \mathrm{~cm}(11,9 \%)$. Estes valores foram bem superiores aos encontrados neste experimento, onde, no resíduo baixo o número de perfilhos decapitados, foi de $8,2 \%$ e no resíduo alto, de apenas $2,4 \%$.

$\mathrm{O}$ número de perfilhos aéreos e basilares remanescentes não apresentou diferença $(\mathrm{P}>0,05)$ entre os resíduos (Tabela 1). O baixo número de perfilhos aéreos remanescentes pode ser atribuído a sua localização na planta que, geralmente, se situa na parte superior, onde apresenta maior chance de ser removido pelo animal. Com o avanço da idade da planta e conseqüente alongamento dos entrenós, as chances de aparecimento de perfilhos aéreos, a partir de gemas localizadas na axila da folha, aumentam. Este alongamento é mais evidente em relvados na fase reprodutiva da planta (Lemaire \& Chapman, 1996), que para esta gramínea ocorre no mês de abril. Por se tratar de uma área recém-formada, é possível que a quantidade de perfilhos aéreos, antes do pastejo, já se 
apresentasse reduzida.

Para perfilhos basilares novos, houve diferença $(\mathrm{P}<0,05)$ entre resíduos, registrando-se maiores valores para o resíduo baixo (Tabela 1). Segundo Lemaire (2001), relvados com desfolhação mais severa tendem apresentar maior quantidade de perfilhos e folhas novas. O número de folhas formadas, no eixo do perfilho, determina o potencial de aparecimento de novos perfilhos, "site filling" (Davies, 1974). Este processo ocorre por meio de gemas localizadas em cada axila de uma folha. Como no resíduo baixo a taxa de aparecimento de folhas foi maior, o aparecimento de novos perfilhos basilares seguiu o mesmo comportamento. No início do período de avaliação, o IAF do relvado permaneceu abaixo de 1,0 (Figura 8). Com isso a taxa de aparecimento de novos perfilhos foi elevada (Figura 5), devido ao aumento da intensidade de luz sob as gemas axilares. Quando o IAF aumentou com os dias após o pastejo, a taxa de aparecimento de novos perfilhos diminuiu, pois a quantidade de luz incidente sobre as gemas axilares foi reduzida (Simon \& Lemaire, 1987). Trabalhando com Aragrostis stolonifera e Lolium perenne, Bullock et al. (1994) verificaram, para as duas espécies, incremento no número de perfilhos novos em pastejos com maior taxa de lotação, porém a taxa de mortalidade também aumentou, não afetando a densidade de perfilhos.

A quantidade de perfilhos basilares novos, nos resíduos alto e baixo, decresceu linearmente com os

Tabela 1 - Número de perfilhos, por touceiras, do capim Tanzânia, nos dois resíduos forrageiros póspastejo, entre 04/11/99 e 16/12/99

Table 1 - Number of tillers, by tussock, of Tanzaniagrass, in the two post grazing stubble, from 11/04/99 to 12/16/99

\begin{tabular}{lccc}
\hline $\begin{array}{l}\text { Tipo de perfilho } \\
\text { Type of tiller }\end{array}$ & \multicolumn{2}{c}{ Resíduos } & $\operatorname{Pr}>\mathrm{F}$ \\
\cline { 2 - 3 } & $\begin{array}{c}\text { Alto } \\
\text { High }\end{array}$ & $\begin{array}{c}\text { Baixo } \\
\text { Low }\end{array}$ & \\
\hline $\begin{array}{l}\text { Decapitado } \\
\text { Decapitated } \\
\text { Aéreo remanescente } \\
\text { Remainingaerial }\end{array}$ & 2,0 & 7,6 & 0,1325 \\
$\begin{array}{l}\text { Basilar remanescente } \\
\text { Remaining basal }\end{array}$ & 76,2 & 7,7 & 0,9590 \\
$\begin{array}{l}\text { Basilar novo } \\
\text { New basal }\end{array}$ & 14,4 & 85,6 & 0,1127 \\
$\begin{array}{l}\text { Aéreo novo } \\
\text { New aerial }\end{array}$ & 3,0 & 16,1 & 0,0438 \\
\hline
\end{tabular}

R. Bras. Zootec., v.31, n.2, p.583-593, 2002 dias após o pastejo (Figura 5), registrando-se reduções de 4 e 5 perfilhos novos a cada oito dias de rebrotação para os resíduos baixo e alto, respectivamente. Podese observar intenso perfilhamento nas duas primeiras semanas após o pastejo, em ambos os resíduos. Os perfilhos basilares novos surgidos na primeira semana contribuíram com 36\% (resíduo baixo) e 39\% (resíduo alto) do total de perfilhos surgidos durante os 35 dias de rebrotação. Já a contribuição dos perfilhos surgidos na última semana foi de 14 e 11\% para os resíduos baixo e alto, respectivamente. De fato, Loch (1985), trabalhando com oito gramíneas tropicais, relatou que o máximo perfilhamento ocorre durante a fase inicial do crescimento vegetativo.

Corsi (1984) verificou intensa concentração na emissão de perfilhos nos primeiros oito dias após o corte em Panicum maximum cv. 68 s-5-2. Também Pinto (1993), trabalhando com os capins-setária e guiné, observou intenso perfilhamento basilar aos 14 dias de rebrotação, independentemente da espécie e das doses de $\mathrm{N}$.

Verificou-se redução no número de perfilhos aéreos novos por touceira com o passar do tempo após a rebrotação (Figura 5). Já na primeira avaliação foram encontrados valores bem inferiores, quando comparados com perfilhos basilares novos, com contribuição de apenas $6 \%$ do total de perfilhos surgidos durante a rebrotação.

Jewiss (1972) relatou que a redução de perfilhamento aéreo ocorre por meio da dominância

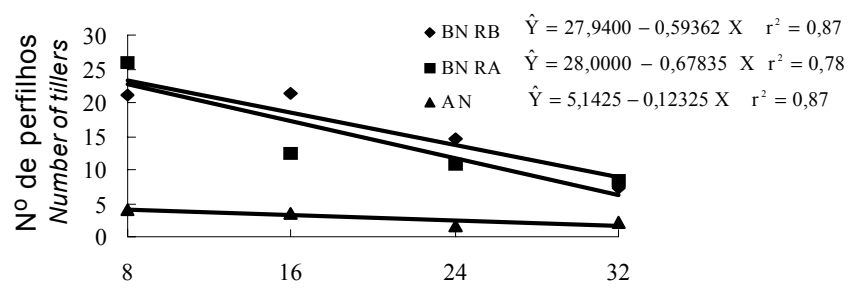

Dias após o pastejo $(X)$ Days after grazing $(X)$

Figura 5 - Número de perfilhos basilares (BN) e aéreos (BA) novos, por touceira, nos resíduos alto (RA) e baixo (RB), em função dos dias (X) após o pastejo.

Figure 5 - Number of new basal and aerial tillers, by tussock, in the high (HPS) and low (LPS) stubbles, as function of days $(X)$ after grazing. 
apical exercida por cada perfilho sobre suas gemas axilares, quando se tem aumento no número de perfilhos basilares.

Houve diferença entre resíduos $(\mathrm{P}<0,01)$ para peso seco de perfilhos, onde este apresentou resposta quadrática em função dos dias após o pastejo (Figura 6). A queda no peso seco de perfilhos, no resíduo baixo, e a estabilização do peso, no resíduo alto, durante a segunda semana, foram conseqüências da falta de chuvas no período, juntamente com infestação de lagarta-do-cartucho (Spodoptera frugiperda), que removeu considerável quantidade de área foliar, influenciando o peso seco por perfilho nesta semana. Após o controle da lagarta, o peso seco de perfilhos aumentou com o avanço do tempo, provavelmente, em função da reestruturação da área foliar e do aumento no peso de colmo.

A diferença no peso seco de perfilhos entre os resíduos pode estar baseada na compensação peso/ densidade de perfilhos (Hodgson, 1990; Hernández Garay et al., 1999). Quando a população de perfilhos é elevada, como no resíduo baixo, estes tendem a apresentar menor peso seco (Figura 6). Já em situação inversa, ou seja, com menor população de perfilhos, estes tendem a apresentar maior peso seco.

\section{Características morfogênicas}

Não houve interação entre resíduo e tipo de perfilho para as variáveis estudadas, exceto para taxa de aparecimento de folhas $\left(\mathrm{TA}_{\mathrm{p}} \mathrm{F}\right)$.

A análise de variância para a taxa de alongamento foliar $\left(\mathrm{TA}_{1} \mathrm{~F}\right)$ não apresentou diferença entre resíduos e entre tipos de perfilho $(\mathrm{P}>0,05)$ (Tabela 2). A TA $\mathrm{F}$ é

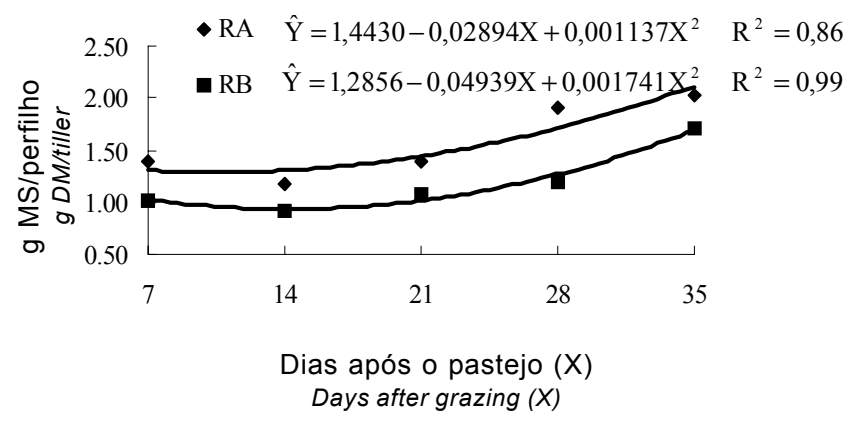

Figura 6 - Peso seco de perfilhos basilares remanescentes nos resíduos alto (RA) e baixo (RB), em função dos dias (X) após o pastejo.

Figure 6 - Dry weight of remaining basal tillers in the high (HPS) and low (LPS) stubbles, as a function of days $(X)$ after grazing. positivamente correlacionada com o rendimento forrageiro (Horst et al., 1978) e o rendimento por perfilho (Nelson et al., 1977), porém negativamente correlacionada com o número de perfilhos por planta (Jones et al., 1979). De acordo com Davies (1974), a $\mathrm{TA}_{1} \mathrm{~F}$ é pouco afetada pela desfolhação e a redução na taxa de alongamento de novas folhas seria afetada em 15 a $20 \%$, quando todas as folhas do perfilho forem removidas. Este resultado demonstra o incremento na força do meristema foliar como dreno de assimilados após a desfolhação. Alterações na TAlF estão diretamente relacionadas com modificações da temperatura sobre o meristema apical (Peacock, 1975) e o nível de nitrogênio (Gastal et al., 1992).

A duração de alongamento foliar (DAlF) apresentou diferenças significativas para resíduo $(\mathrm{P}<0,01)$, e tipo de perfilho $(\mathrm{P}<0,05)$ (Tabela 2). A menor duração de alongamento foliar no resíduo baixo pode ser atribuída à maior taxa de lotação deste tratamento, onde ocorre menor seletividade, que promove maior remoção de tecidos foliares e pseudocolmo (Parsons, 1988), o que implicaria em pseudocolmos menores. Dessa forma, a distância percorrida pela folha do meristema apical até a extremidade do pseudocolmo seria menor, justificando assim o rápido alongamento de folhas até sua completa expansão e conseqüente menor $\mathrm{DA}_{1} \mathrm{~F}$.

$\mathrm{A} \mathrm{DA}_{1} \mathrm{~F}$ em relação ao tipo de perfilho apresentou diferença $(\mathrm{P}<0,01)$, em que os perfilhos novos tiveram menor duração de alongamento em relação aos perfilhos remanescentes (Tabela 2). Uma vez que a DAlF depende diretamente da taxa de alongamento de folhas e do comprimento final destas (Lemaire \& Agnusdei, 1999), pode-se inferir que, para o tipo de perfilho, além do menor comprimento de pseudocolmo, o comprimento final de folhas influenciou a $\mathrm{DA}_{1} \mathrm{~F}$ (Tabela 2), sendo que o perfilho novo apresentou menor comprimento final e conseqüente menor $\mathrm{DA}_{1} \mathrm{~F}$.

A taxa de senescência (TS) não apresentou diferença entre resíduos e tipo de perfilho $(\mathrm{P}>0,05)$ (Tabela 2). O processo de senescência de folhas nos perfilhos remanescentes, nos dois resíduos, ocorreu somente nas folhas que foram em parte consumidas pelos animais, não sendo verificada nas folhas que surgiram durante os 35 dias de descanso, onde foram realizadas as avaliações. Assim, foram encontradas folhas em senescência logo na primeira semana após o pastejo. No perfilho novo, o primeiro sinal de senescência na folha ocorreu no sexto dia após o seu 
Tabela 2 - Valores médios para taxa de alongamento foliar (TA,F), duração de alongamento foliar (DA, $F$ ), taxa de senescência (TS) e comprimento final de folha (CF), em função do tipo de perfilho e do resíduo forrageiro póspastejo

Table 2 - Average values for leaf elongation rate (LER), leaf elongation duration (LED), senescence rate (SR) and final leaf lenght (FLL), in function of the type of tiller and the post grazing stubble

\begin{tabular}{|c|c|c|c|c|c|c|}
\hline & \multicolumn{2}{|c|}{$\begin{array}{l}\text { Tipo de perfilho } \\
\text { Kind of tiller }\end{array}$} & \multirow[b]{2}{*}{$\operatorname{Pr}>\mathrm{F}$} & \multicolumn{2}{|c|}{$\begin{array}{l}\text { Resíduo } \\
\text { Stubble }\end{array}$} & \multirow[b]{2}{*}{$\operatorname{Pr}>F$} \\
\hline & $\begin{array}{l}\text { Novo } \\
\text { New }\end{array}$ & $\begin{array}{c}\text { Remanescente } \\
\text { Remaining }\end{array}$ & & $\begin{array}{l}\text { Alto } \\
\text { High }\end{array}$ & $\begin{array}{l}\text { Baixo } \\
\text { Low }\end{array}$ & \\
\hline $\begin{array}{l}\mathrm{TA}_{1} \mathrm{~F} \text { (cm.dia/perfilho) } \\
\text { LER (cm.day/tiller) }\end{array}$ & 1,865 & 2,005 & 0,5728 & 1,984 & 1,887 & 0,6422 \\
\hline $\begin{array}{l}\mathrm{DA}_{1} \mathrm{~F} \text { (dias) } \\
L E D \text { (Days) }\end{array}$ & 7,3 & 8,9 & 0,0280 & 9,2 & 7,1 & 0,0003 \\
\hline $\begin{array}{l}\text { TS (cm.dia/perfilho) } \\
S R \text { (cm.day/tiller) }\end{array}$ & 1,182 & 1,399 & 0,2690 & 1,336 & 1,244 & 0,7535 \\
\hline $\begin{array}{l}\mathrm{CF}(\mathrm{cm}) \\
F L L(\mathrm{~cm})\end{array}$ & 20,94 & 29,20 & 0,0064 & 26,75 & 23,39 & 0,3289 \\
\hline
\end{tabular}

completo alongamento e sua morte ocorreu no décimo quarto dia. As folhas que primeiramente senesceram foram aquelas localizadas nos níveis de inserção inferiores. Robson et al. (1988) relataram que folhas dos níveis inferiores de inserção são menores que as do nível superior. Assim, a taxa de senescência foliar permanece menor que a taxa de produção de novos tecidos. À medida que a senescência atinge folhas do nível de inserção superior, ou seja, folhas maiores com tamanho relativamente constante, a produção líquida de forragem se estabiliza, quando a taxa de senescência se iguala ao crescimento foliar (Lemaire, 1997). A partir do $23^{\circ}$ dia, no perfilho novo, o processo de senescência se intensificou, provavelmente pela elevação do IAF, que promove o sombreamento das folhas dos níveis de inserção inferior. De modo geral, a senescência de folhas não é afetada pela desfolhação, e sim pelas características do ambiente, principalmente déficit hídrico (McIvor, 1984) e temperatura (Lemaire \& Chapman, 1996).

O comprimento final de folhas $(\mathrm{CF})$ por perfilho aos 35 dias não apresentou diferenças significativas entre tratamentos $(\mathrm{P}>0,05)$, porém diferiu $(\mathrm{P}<0,01)$ entre tipos de perfilho (Tabela 2), registrando-se maior comprimento no perfilho remanescente. As diferenças no comprimento final de folhas podem ser atribuídas aos valores de $\mathrm{TA}_{\mathrm{p}} \mathrm{F}$; maiores valores para esta variável tendem a produzir maior número de folhas curtas por perfilho e incremento no número de perfilhos. Quando a taxa de aparecimento de folhas do relvado é reduzida, este tende a produzir menor número de folhas, porém mais longas, e menor número de perfilhos (Lemaire \& Agnusdei, 1999). Segundo estes mesmos autores, o comprimento final de folhas também pode ser influenciado pela taxa de alongamento de folhas e duração de alongamento foliar.

Para a taxa de aparecimento de folhas $\left(\mathrm{TA}_{\mathrm{p}} \mathrm{F}\right)$, houve interação $(\mathrm{P}<0,05)$ entre tratamento e tipo de perfilho. Dessa forma, no resíduo baixo, a $\mathrm{TA}_{\mathrm{p}} \mathrm{F}$ do perfilho novo foi maior $(\mathrm{P}<0,05)$ que no perfilho remanescente. Em contrapartida, verificou-se o comportamento inverso no resíduo alto, onde a $\mathrm{TA}_{\mathrm{p}} \mathrm{F}$ foi maior $(\mathrm{P}<0,05)$ no perfilho remanescente (Tabela 3$)$. Na comparação do resíduo forrageiro em cada tipo de perfilho, observou-se que a $\mathrm{TA}_{\mathrm{p}} \mathrm{F}$ no resíduo baixo foi superior $(\mathrm{P}<0,05)$ ao resíduo alto, tanto no perfilho novo quanto no remanescente (Tabela 3 ). Parsons et al. (1991), trabalhando em pastagem consorciada de azevém perene e trevo branco, constataram que a medida em que a altura de corte aumentou de 3 para

Tabela 3 - Taxa de aparecimento de folhas por perfilhos $\left(T A_{p} F\right)$ de perfilhos novos e remanescentes nos resíduos alto e baixo

Table 3 - Leaf appearance rate (LAR) per tiller of new and remaining tillers in the high and low stubbles

\begin{tabular}{lcc}
\hline & $\begin{array}{c}\text { Resíduo alto } \\
\text { High stubble }\end{array}$ & $\begin{array}{c}\text { Resíduo baixo } \\
\text { Low stubble }\end{array}$ \\
\hline $\begin{array}{l}\text { Perfilho novo } \\
\text { New tiller }\end{array}$ & $0,144^{\mathrm{Bb}}$ & $0,182^{\mathrm{Aa}}$ \\
$\begin{array}{l}\text { Perfilho remanescente } \\
\text { Remaining tiller }\end{array}$ & $0,152^{\mathrm{Ba}}$ & $0,171^{\mathrm{Ab}}$ \\
\hline
\end{tabular}

Médias seguidas de letras iguais, maiúsculas nas linhas e minúsculas nas colunas, não diferem $(P>0,05)$ pelo teste $F$. Means followed by the same letter, capital in the row and small in the column, are not different $(P>.05)$ by $F$ test. 
$9 \mathrm{~cm}$, a TA $\mathrm{p}_{\mathrm{p}} \mathrm{F}$ decresceu no azevém perene, porém manteve-se constante no trevo branco.

A TA $\mathrm{p}_{\mathrm{p}} \mathrm{F}$ exerce papel importante na morfogênese, pois afeta todos os componentes que formam a estrutura do relvado. Além disso, Davies (1974) relatou que a $\mathrm{TA}_{\mathrm{p}} \mathrm{F}$ determina a taxa de aparecimento de gemas com potencial para o aparecimento de novos perfilhos "site filling". Maiores taxas de aparecimento de folhas no resíduo baixo e perfilhos novos podem ser explicadas pelo menor tamanho de folhas e menor comprimento de pseudocolmo. Ainda, altas $\mathrm{TA}_{\mathrm{p}}$ F promovem alta densidade de pequenos perfilhos, o que pode ser comprovado na maior taxa de aparecimento de novos perfilhos encontrados no resíduo baixo (Tabela 1). Baixas densidades e maiores perfilhos são encontrados sob baixas $\mathrm{TA}_{\mathrm{p}} \mathrm{F}$ e, na comparação entre resíduos, isto fica evidente por meio da observação do peso seco de perfilhos que foi maior no resíduo alto (Figura 6).

Acúmulo de matéria seca verde e relação folha:colmo

A taxa de acúmulo de matéria seca verde (AMSV) não diferiu $(\mathrm{P}>0,05)$ entre resíduos, onde os valores médios foram de 61,4 e 47,9 kg MSV/ha.dia, nos resíduos baixo e alto, respectivamente. De fato, Bircham \& Hodgson (1983) relataram que a taxa líquida de produção de forragem é insensível às mudanças na biomassa do relvado, entre os limites práticos do manejo de pastagem. O acúmulo de forragem pode ser atribuído ao incremento na densidade ou no peso de perfilhos ou à combinação de ambos (Nelson \& Zarrough, 1981). Embora o acúmulo de forragem possa ser explicado pela densidade e pelo peso de perfilhos, também é reconhecido que a população de perfilhos está sujeita à compensação tamanho/densidade (Chapman \& Lemaire, 1993). Infere-se, portanto, que, em biomassa crescente, pode haver aumento de tamanho do perfilho e redução na sua população, não alterando a produtividade do relvado. Similarmente, o incremento na população de perfilhos, em função da redução de sua biomassa, novamente não implica em alteração na produtividade (Hernández Garay et al., 1999). Resposta semelhante foi encontrada neste experimento, no qual o resíduo baixo apresentou maiores taxas de perfilhamento e menor peso seco de perfilhos (Figuras 5 e 6).

A relação folha:colmo apresentou diferença $(\mathrm{P}<0,01)$ entre os resíduos forrageiros. Em ambos os resíduos, a relação folha:colmo apresentou resposta linear positiva, em função dos dias após o pastejo, onde foram estimados valores de 1,52 e 0,75 aos sete dias e 3,66 e 3,56 aos 35 dias para os resíduos alto e baixo, respectivamente (Figura 7). O maior valor inicial obtido para o resíduo alto foi em função da menor taxa de lotação empregada, o que permitiu maior quantidade de resíduo foliar pós pastejo. Os altos valores obtidos, ao final do ciclo de pastejo, podem ser atribuídos à elevada porcentagem de folha desta cultivar, que, segundo Savidan et al. (1990), é de $80 \%$ durante o ano. $\mathrm{O}$ valor encontrado para o resíduo baixo aos 35 dias $(3,56)$ é praticamente semelhante ao resíduo alto, ressaltando o grande potencial de recuperação desta gramínea após a desfolhação.

\section{Índices de crescimento}

$\mathrm{O}$ índice de área foliar (IAF) não diferiu entre resíduos $(\mathrm{P}>0,05)$, porém apresentou resposta quadrática em função dos dias de rebrotação, estimando-se valor mínimo de 0,52 aos nove dias (Figura 8). Isto pode ser atribuído ao ataque da lagarta do cartucho, como discutido anteriormente.

Segundo Chapman \& Lemaire (1993), a combinação das características estruturais do relvado, como tamanho de folhas, densidade de perfilhos e folhas por perfilho, determina o IAF. Este é o principal fator influenciando a interceptação de luz e, portanto, a dinâmica de rebrota do relvado. Dessa forma, quando

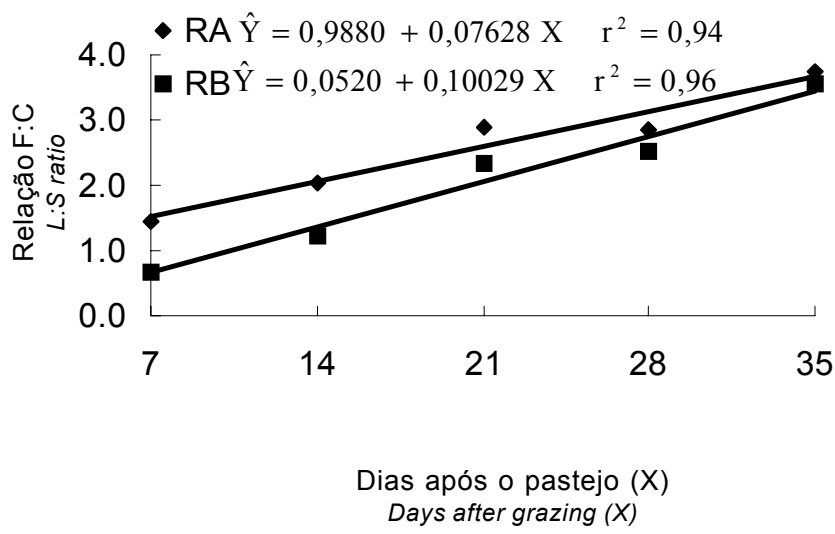

Figura 7 - Relação folha:colmo do capim-tanzânia nos resíduos alto (RA) e baixo (RB), em função dos dias (X) após o pastejo.

Figure 7 - Leaf:stem ratio of Tanzaniagrass in the high (HPS) and low (LPS) stubbles, as a function of days ( $X$ ) after grazing. 


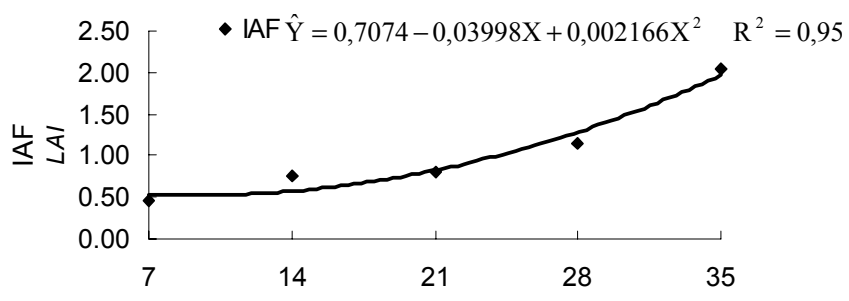

Dias após o pastejo $(X)$

Days after grazing $(X)$

Figura 8 - Estimativa do índice área foliar (IAF) nos resíduos forrageiros pós-pastejo em função dos dias (X) após o pastejo.

Figure 8 - Leaf area index (LAI) in the post grazing stubbles, as a function of days $(X)$ after grazing.

o IAF é baixo, como no início de avaliação (Figura 8), a incidência de luz sobre as gemas axilares é maior, estimulando o perfilhamento e, como conseqüência, novas folhas se desenvolvem com alta capacidade fotossintética (Woledge, 1978). Com o aumento do IAF, a fotossíntese e a produção bruta de forragem apresentam-se próximas do máximo (Parsons, 1988). Isto porque a grande quantidade de tecido presente no relvado contribui para a alta taxa de fotossíntese, porém também contribui para altas taxas de perda de material pela senescência e morte de folhas e perfilhos. Segundo Grant et al. (1983), a taxa de senescência e morte de tecidos do relvado aumenta linearmente com o incremento no IAF. Assim, a produção de forragem pode diminuir, como demonstrado na Figura 9, por intermédio da redução da taxa de crescimento relativo (TCR) na última semana de avaliação.

A TCR não variou ( $\mathrm{P}>0,05)$ entre resíduos, onde os valores médios foram de 0,14 e $0,06 \mathrm{~g} / \mathrm{g}$.dia nos resíduos, baixo e alto, respectivamente. Entretanto, nenhum modelo proposto ajustou-se aos dados para explicar o comportamento desta variável em função dos dias de rebrotação. A taxa de crescimento relativo (TCR) apresentou tendência linear negativa com o passar dos dias após o pastejo (Figura 9).

De acordo com Lawlor (1995), o rendimento forrageiro, que pode ser mensurado pela TCR, apresenta melhor correlação com as características do relvado (IAF), associadas à interceptação de luz, do que com a eficiência fotossintética da planta. Assim,

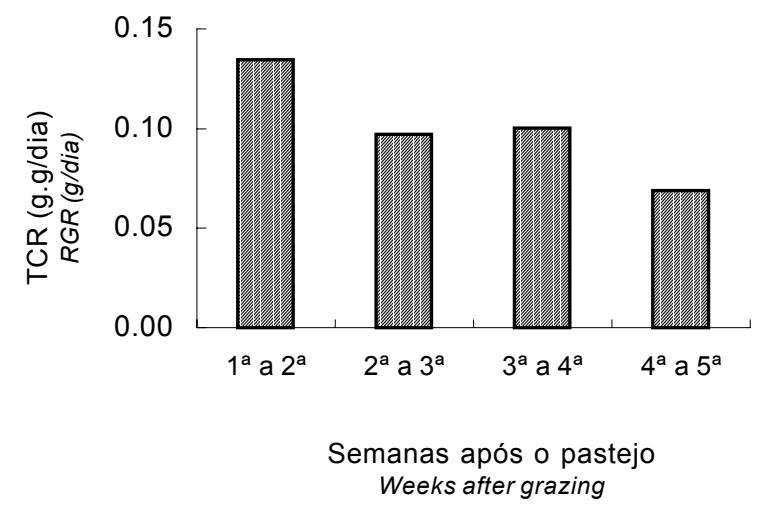

Figura 9 - Taxa de crescimento relativo (TCR) nos dois resíduos forrageiros pós-pastejo em função das semanas após o pastejo.

Figure 9 - Relative growth rate (RGR) in the post grazing stubbles, in function of days $(X)$ after grazing.

a TCR (Figura 9) apresentou comportamento inverso do IAF (Figura 8). O maior valor para TCR na primeira semana de avaliação reflete o intenso crescimento da planta no início da fase de rebrotação.

Os valores encontrados neste experimento estão condizentes com Beadle (1993), segundo o qual o valor máximo da TCR é de $0,5 \mathrm{~g} / \mathrm{g}$.dia para a maioria das espécies de plantas $\mathrm{C}_{4}$.

Resultados semelhantes para TCR foram encontrados por Pinto (1993), na ordem de 0,20 g.g/dia, em capim-guiné, e por Ludlow \& Wilson (1970), em Brachiaria ruzizenses, na primeira semana após a semeadura, com valor de 0,155 g.g/dia. Beretta et al. (1999), trabalhando no campo, encontraram valores médios de TCR, para a mesma cultivar, de 0,027 e 0,039 g.g/dia nos períodos seco e chuvoso, respectivamente.

\section{Conclusões}

Foram verificadas adaptações morfofisiológicas, ou seja, uma resposta plástica do relvado, em função dos resíduos utilizados, fazendo com que não ocorressem diferenças no acúmulo líquido de forragem. O resíduo baixo apresentou elevadas taxas de aparecimento de folhas e perfilhos novos, não havendo comprometimento da rebrotação do pasto. Os resultados obtidos indicaram não haver diferença no potencial produtivo forrageiro entre os resíduos estudados. 


\section{Literatura Citada}

BEADLE, C.L. Growth analysis In: HALL, D.O., BOLHARNORDENKAMPF, H.R., LEEGOOD, R.C., LONG, S.P. (Eds.) Photosynthesis and production in a changing environment: a field and laboratory manual. London: Chapman \& Hall, 1993. p.36-46.

BERETTA, L.G.R.; KANNO, T.; MACEDO, M.C.M. et al. Morfogênese foliar e taxas de crescimento de pastagens de Panicum maximum cv. Tanzânia-1 em solos dos cerrados In: REUNIÃO ANUAL DA SOCIEDADE BRASILEIRA DE ZOOTECNIA, 36., 1999, Porto Alegre. Anais... Porto Alegre: SBZ, 1999. (CD ROM). Forragicultura. FOR-130.

BIRCHAM, J.S.; HODGSON, J. The influence of sward condition on rates of herbage growth and senescence in mixed sward under continuous stocking management. Grass and Forage Science, v.38, n.4, p.323-331, 1983.

BULLOCK, J.M.; HILL, C.J.; SILVERTOWN, J. Tiller dynamics of two grasses - responses to grazing, density and weather. Journal of Ecology, v.82, p.331-340, 1994.

CHAPMAN, D.F.; LEMAIRE, G. Morphogenetic and structural determinants of plants regrowth after defoliation. In: INTERNATIONAL GRASSLAND CONGRESS, 17. 1993, New Zealand. Proceedings... New Zealand, 1993. p.93-104.

COELHO,E.M.; CECATO U.; BARBOSA, M.A.A.F. et al. Características do perfilhamento em quatro cultivares de Panicum maximum jacq. In: REUNIÃO ANUAL DA SOCIDADE BRASILEIRA DE ZOOTECNIA, 36, 1999. Porto Alegre. Anais... Porto Alegre: Sociedade Brasileira de Zootecnia, 1999. (CD ROM). Forragicultura. FOR-096.

CORSI, $M$. Effects of nitrogen rates and harvesting intervals on dry matter productivity, tillering and quality of tropical grass Panicum maximum Jacq. Wooster: Ohio State University, 1984. 125p. These (Ph.D.) - Ohio State University, 1984.

DAVIES, A. Leaf tissue remaining after cutting and regrowth in perennial ryegrass. Journal of Agriculture Science, v.82, p.165-172, 1974.

GASTAL, F.; BÉLANGER, G.; LEMAIRE, G. A model of leaf extension rate of tall fescue in response to nitrogen and temperature. Annals of Botany, v.70, p.437-442, 1992.

GRANT, S. A.; BARTHRAM, G.T.; TORVELL, L. et al. Sward management, lamina turnover and tiller population density in continuously stocked Lolium perene-dominated swards. Grass and Forage Science, v.38, p.333-344, 1983.

GRANT, S.A.; MARRIOT, C.A. Detailed studies of grazed swards - techniques and conclusions. Journal of Agriculture Science, v.122, p.1-6, 1994.

HERNÁNDEZ GARAY, A.; MATTHEW, C.; HODGSON, J. Tiller size density compensation in perennial ryegrass miniature swards subject to differing defoliation heights and a proposed productivity index. Grass and Forage Science, v.54, p.347-356, 1999.

HODGSON, J. Grazing management: science into practice. New York: Longman Handbooks in Agriculture, 1990. 200p.

HORST, G.L.; NELSON, C.J.; ASAY, K.H. Relationship of leaf elongation to forage yield of tall fescue genotypes. Crop Science, v.18, p.715-719, 1978.
JEWISS, O.R. Tillering in grasses - its significance and control. Journal British Grassland Society, v.27, n.2, p.65-82, 1972 .

JONES, R.J.; NELSON, C.J.; SLEPER, D.A. Seedling selection for morphological characters associated with yield of tall fescue. Crop Science, v.19, p.367-372, 1979.

LANGER, R.H.M. How grasser grow. London: Edwards Arnold, 1972. 60p. (Studies in Biology, 34).

LAWLOR, D.W. Photosynthesis, productivity and environment. Journal of Experimental Botany, v.46, p.1449-1461 (special issue), 1995.

LEMAIRE, G. Ecophysiology of grasslands: dynamic aspects of forage plant population in grazed swards. In: INTERNATIONAL GRASSLAND CONGRESS, 19., 2001, Piracicaba. Proceedings... Piracicaba, Fundação de Estudos Agrários "Luiz de Queiroz", 2001. p.29-38.

LEMAIRE, G. The physiology of grass growth under grazing: tissue turnover. In: SIMPÓSIO INTERNACIONAL SOBRE PRODUÇÃO ANIMAL EM PASTEJO, Viçosa, MG, 1997. Anais... Viçosa: Universidade Federal de Viçosa, 1997. p.115-144.

LEMAIRE, G.; CHAPMAN, D.F. Tissue flows in grazed communities. In: HODGSON, J.; ILLIUS, A.W. (Eds.). The ecology and management of grazing systems. Walling ford: CAB International, 1996. p.3-37.

LEMAIRE, G.; AGNUSDEI, M. Leaf tissue turn-over and efficiency of herbage utilization. In: SIMPÓSIO INTERNACIONAL "GRASSLAND ECOPHYSIOLOGY AND GRAZING ECOLOGY”, 1999, Curitiba. Anais.... Curitiba: Universidade Federal do Paraná, 1999. p.165-186.

LOCH, D.S. Tiller development in relation to seed production of tropical grasses. In: INTERNATIONAL GRASSLAND CONGRESS, 15., Kyoto, 1985. Proceedings... Kyoto, s.ed., 1985. p.264-266.

LUDLOW, M.M.; WILSON, G.L. Studies of the productivity of tropical pasture plants. II. Growth analysis, photosynthesis, and respiration of 20 species of grasses and legumes in a controlled environment. Australian Journal of Agriculture Research, v.21, n.2, p.183-194, 1970.

McIVOR, J.G. Leaf growth and senescence in Urochloa mosambicensis and U. oligotricha in a seasonally dry tropical environment. Australian Journal of Agriculture Research, v.35, p.177-187, 1984.

NELSON, C.J.; ASAY, K.H.; SLEPER, D.A. Mechanisms of canopy development of tall fescue genotypes. Crop Science, v.17, p.449-452, 1977.

NELSON, C.J.; ZARROUGH, K.M. Tiller density and tiller weight as yield determinants of vegetative swards. In: WRIGHT, C.E. (Ed.) Plant physiology and herbage production. Hurley: British Grassland Society, 1981. p.25-29.

PARSONS, A.J. The effects of season and management on the growth of grass swards. In: JONES, M.B., LAZENBY,A. (Eds.) The grass crop: the physiological basis of production. London: Chapman \& Hall, 1988. p.129-177.

PARSONS, A.J.; ANNE, H.; WOLEDGE, J. Plant/animal interactions in continuously grazed mixtures: 1 . Differences in the physiology of leaf expansion and the fate of leaves the grass and clover. Journal of Applied Ecology, v.28, p.619-634, 1991 . 
PEACOCK, J.M. Temperature and leaf growth in Lolium perene. 1. The thermal microclimate: its measurement and relation to plant growth. Journal of Applied Ecology, v.12, p.115-123, 1975.

PINTO, J.C. Crescimento e desenvolvimento de Andropogon gayanus Kunth, Panicum maximum Jacq. e Setaria anceps Stapf ex Massey cultivadas em vasos, sob diferentes dozes de nitrogênio. Viçosa, MG: Universidade Federal de Viçosa, 1993. 149p. Tese (Doutorado em Zootecnia) - Universidade Federal de Viçosa, 1993.

ROBSON, M.J.; RYLE, G.J.A.; WOLEDGE, J. The grass plant its form and function. In: JONES, M.B., LAZENBY, A. (Eds.) The grass crop: the physiological basis of production. London: Chapman \& Hall, 1988. p.25-83.

SAS INSTITUTE. SAS/STAT. User's guide statistics, versão 6, 4. ed., Cary, USA: v.1,2. 1993.

SAVIDAN, Y.H.; JANK, L.; COSTA, J.C.G. Registros de 25 acessos selecionados de Panicum maximum. Campo Grande: EMBRAPA, CNPGC, 1990. 68p. (EMBRAPA - CNPGC. Documentos, 44).
SIMON, J.C.; LEMAIRE, G. Tillering and leaf area index in grasses in the vegetative phase. Grass and Forage Science, v.42, n.4, 373-380, 1987.

VALENTINE I.; MATTWEW, C. Plant growth, development and yield. In: WHITE, J., HODGSON, J. (Eds). New Zealand pasture and crop science. Oxford: Oxford University Press, 1999. p.11-28.

WOLEDGE, J. The effect of shading during vegetative and reproductive growth on photosynthetic capacity of leaves in a grass sward. Annals of Botany, v.42, n.181, p.1085-1089, 1978.

Recebido em: 12/06/01

Aceito em: 18/12/01 